\title{
Use of Callendar's "Radio-Balance" for the Measurement of the Energy Emission from Radioactive Sources
}

\author{
W. B. Mann
}

In 1910 H. L. Callendar described a calorimeter for measurement of radiant energy in which the quantity of heat to be measured is balanced against the cooling from a Peltier couple. He called this thermal-balance device a "radio-balance." The operation of the radio-balance has been extensively investigated to see whether it could be used for the accurate determination of the energy emission from radioactive sources. In the present experiments, measurements have been confined solely to radium preparations. For an absorption equivalent to $0.126 \mathrm{~cm}$ of lead a heat emission of $128.9 \mathrm{cal} \mathrm{g}^{-1} \mathrm{hr}^{-1}$ has been found for radium in equilibrium with its products down to radium D. The estimated accuracy of this result is \pm 0.7 percent.

\section{Introduction}

In 1910 , in a paper that seems to have caused little interest in the intervening years, H. L. Callendar $[1],{ }^{1}$ described a calorimeter in which the quantity of heat to be measured was to be balanced by the cooling from a Peltier couple. With this calorimeter, which he called a radio-balance ${ }^{2}$ because it gave a null reading, he made measurements of the solar radiation, and he also carried out a somewhat rudimentary measurement of the energy emitted in unit time from a sealed source of radon emanation lent to him for the purpose by Lord Rutherford. The results obtained with the emanation, although qualitatively interesting, were not of great value from a quantitative point of view.

1 Figures in brackets indicate the literature references at the end of the paper. 2 This instrument should perhaps be renamed the "Radiation Balance."
Some 20 vears later Hoare [2, 3] used a radiobalance to determine the Stefan-Boltzmann radiation constant. This appears to be the only other recorded application of the radio-balance, and no other reference to it in the scientific literature of the last 23 years has been found. It seems, however, that this method of determining the energy dissipation has much to commend itself, and experiments have recently been carried out to see whether or not it might be feasible to apply it to determine the rate of energy production by radioactive sources. For this purpose, several radio-balances were constructed. The outstanding merit of this form of microcalorimeter is its extreme compactness, the first simple version used in the experiments here described being contained in a cylindrical copper box only $2 \frac{1}{8}$ in. high and $2 \mathrm{in}$. in diameter, whereas the final version was contained in what was essentially a cylindrical copper block $2 \frac{1}{4} \mathrm{in}$. in height and $4 \mathrm{in}$. in diameter. These are shown in figure 1.


FIGURE 1. Three radio-balances.


radio-balance is that with four Peltier junctions. 


\section{Theory}

In the radio-balance the energy incident upon, or transmitted to, a small disk or cup is balanced by the cooling effected by a Peltier junction attached to the same disk or cup. Callendar used both a disk and a cup radio-balance as a pyrheliometer, and Hoare used a cup balance to measure the StefanBoltzmann radiation constant.

In the present experiments a cup-type radiobalance was used, consisting, in its final version, of two copper cups $13 / 16$ in. long and having internal and external diameters of 0.099 and 0.130 in., respectively. Each cup was mounted on a sixjunction constantan-chromel thermopile by means of an equatorial ring, as illustrated in figure 2 . The lower junctions of each thermopile dip into silicone vacuum oil contained in two small cavities in the lower copper block constituting the container of the radio-balance. A constantan-chromel Peltier couple is soldered to the base of each cup.

The radio-balance may be used in two ways. Each cup may be used singly, or they may be used together in opposition. In the present experiments the interest has lain in the measurement of the energy emission from radioactive sources and not of energy flux from an external source of radiation. Such a radioactive source, as, for example, a radium needle, may be placed in either cup A or cup B of the radio-balance and a current passed through the Peltier junction in such a direction and of such magnitude that the cooling due to the Peltier junc-

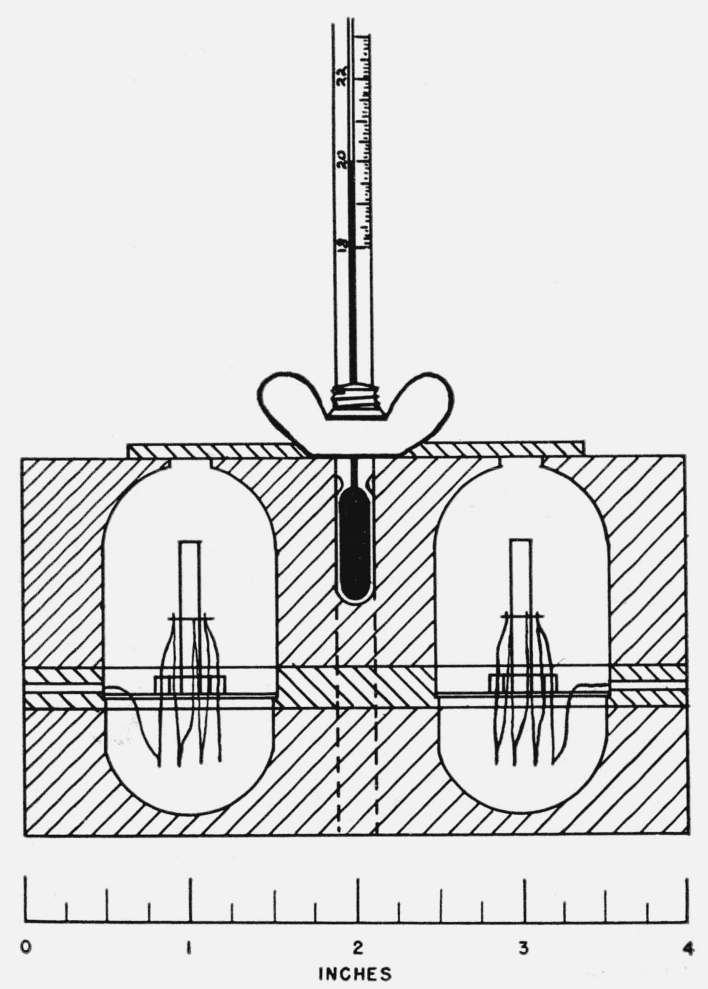

FIGURE 2. Elevation drawing through the vertical axis of symmetry of the third and final radio-balance. tion shall exactly balance the heating due to the radioactive preparation. The criterion for such balance is obtained by reducing to zero the deflection of a sensitive galvanometer connected to the thermopile. For zero deflection, the temperature of the cup is restored to the same temperature as the base of the thermopile, and there should be an exact balance between the heat energy supplied to the cup by the radioactive source and the heat removed by the Peltier cooling. In this condition the energy, $H$, supplied by the radioactive source is given by

$$
H=P C-C^{2} R,
$$

where $P$ is the Peltier coefficient, $C$ is the current passing through the Peltier junction, and $R$ is its resistance.

In order to determine the resistance of the Peltier junction, a subsidiary experiment may be carried out, in which a dummy source is substituted for the radioactive source, in order to simulate external heat-loss conditions and the thermal conductivity along the length of the cup, and the current is again adjusted to give zero deflection of the thermopile galvanometer. In this condition

or

$$
0=P C-C^{2} R,
$$

$$
R=P / C \text {. }
$$

By differentiation of eq (1) it is clear that the maximum cooling effect that can be obtained is

$$
H=P^{2} / 4 R \text {. }
$$

In the second method of using the radio-balance the thermopiles of cup A and cup B are connected in series with one another and with the galvanometer so as to act in opposition to each other. Thus an equal rise in temperature of both cup A and cup B relative to the thermopile bases will give a zero galvanometer deflection. The Peltier junctions are also connected in opposition and in series, so that the same current flows through each but will cause a heating in the one cup and a cooling in the other.

In all the radio-balances that have been constructed in this investigation a small residual galvanometer deflection was almost invariably detected, indicating a slight temperature difference between cup A or cup B and the thermopile bases, with no source in either cup and no Peltier current flowing. This could be due to a very slight difference in temperature between the top and bottom of the copper block container. With the piles of cup A and cup B connected in opposition, however, the "zero deflection" was invariably negligible, any slight rise in temperature in cup A being compensated for by a similar rise in cup $\mathrm{B}$.

In this second method of using the radio-balance, which was also proposed by Callendar, another advantage derives from the fact that the Joule heating of the Peltier junctions is also eliminated. To describe this method, assume that a radioactive 
source dissipating energy $W^{\prime}$ watts is placed in cup $A$ and that another dissipating $W^{\prime \prime}$ watts is placed in $\operatorname{cup}$ B. If a dummy is used in cup B, then $W^{\prime \prime}$ is zero, but this is not necessarily so, and the method can in fact be used to compare two nearly equal sources without involving the use of Peltier cooling or heating at all. This appears to be a new and very accurate application of the radio-balance, as will be demonstrated by the experimental results obtained. This application would certainly have been most apparent to Callendar from his derivation of the relevant equations; the need for such an application did not, however, exist to the same extent more than 40 years ago.

It will be assumed that $W^{\prime}$ is greater than $W^{\prime \prime}$ and that a current $C$ is passed through the Peltier junctions in such a direction as to give a cooling of cup $A$ and a heating of cup B. The value of $C$ is then adjusted to give an approximately zero balance of the thermopile galvanometer. Suppose, however, that the residual galvanometer deflection is $d_{1}$. The sources $W^{\prime}$ and $W^{\prime \prime}$ are now interchanged between cup $\mathrm{A}$ and cup B and the current $C$ is reversed so that cup $A$ is now heated and cup B is cooled. As slight differences will exist between cup A and cup $B$, a new residual galvanometer deflection, $d_{2}$, will be observed. Under these conditions Callendar showed that

$$
W^{\prime}-W^{\prime \prime}=2 P C+\left(d_{1}-d_{2}\right) / s,
$$

where $s$ is the galvanometer-scale sensitivity in millimeters per microwatt transferred from cup A to $\operatorname{cup} \mathrm{B}$, and $P$ is the average of the values of $P_{A}$ and $P_{B}$ for the individual cups. In the final version of the radio-balance used in these experiments, $s$ was of the order of $0.7 \mathrm{~mm} / \mu \mathrm{w}$ when the current through the galvanometer was reversed. That a reversal of the current does, in fact, correspond to a transfer of energy equal to $2 P C$ from the one cup to the other is clear from the energy-dissipation-level diagram in figure 3 , which refers to either cup A or cup B. If cup A gains $2 P C$, then eup B correspondingly loses $2 P C$. The value of $R$ in figure 3 would be that appropriate to cup $\mathrm{A}$ or $\operatorname{cup} \mathrm{B}$.

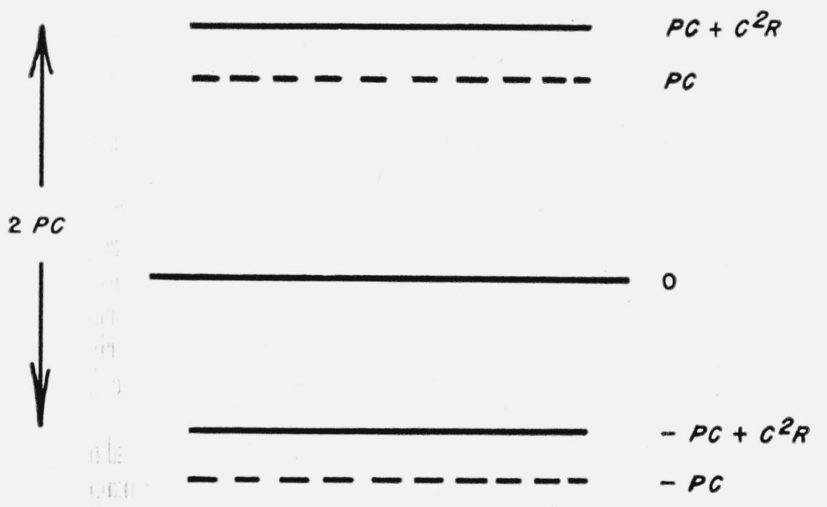

FIGURE 3. Energy-dissipation-level diagram illustrating the elimination of Joule heating on reversal of the current through the Peltier junction of either cup.

\section{Experimental Procedure}

The cups of the third, and final, radio-balance were constructed from copper and were 0.099-in. internal diameter, 0.130-in. external diameter, and $13 / 16$ in. long. The cups were supported on the upper end of a six-junction chromel-constantan thermopile by means of an equatorial annular ring with six small holes. The junctions of the thermopile were insulated from each of the cups by means of six disks of rubber hydrochloride, 0.0002 in. thick, which were cut out by means of a paper punch. The junctions were then sealed in position by means of a small amount of glyptal.

The Peltier junctions are secured to the lower ends of the radio-balance cups by means of soft solder. The Peltier-junction assembly consisted of a framework of four wires in the form of a Cleopatra needle silver-soldered at the apex. A constantan wire and a chromel wire, each 0.020 in. in diameter, along opposite corners of the needle formed the actual Peltier junction. The other two wires formed a thermocouple, by means of which the lowering in temperature of the Peltier junction could be measured. These consisted of constantan and chromel $0.010 \mathrm{in}$. and $0.012 \mathrm{in}$. in diameter, respectively. When assembled each cup stood upon the apex of the Cleopatra needle in the manner indicated in figure 4.

The thermopiles were constructed with the help of a number of lucite annuli of $3 / 8$-in. external diameter, $7 / 32$-in. internal diameter, and $3 / 32$ in. thick. Twelve small holes were drilled through each of these annuli



Figure 4. "Cleopatra-needle" assembly:of Peltier junction and thermocouple for measuring the temperature of the Peltier junction. 
parallel to the axis and at 30-deg intervals. Alternate 0.010-in. diameter constantan and 0.012-in diameter chromel wires, 6 lengths of each, were now threaded through the 12 holes of 6 of these annuli in series. The annuli were separated by some $2 \frac{1}{2}$ in. from each other along the wires and secured to the wires by painting with glyptal cement. When the glyptal hardened the wires were cut midway between each anulus, and the basic units for six thermopiles were obtained. A thermopile was then simply obtained by hard-soldering adjacent constantan and chromel wires at each end in such a manner as to give one continuous circuit.

The cup and thermopile assemblies were finally mounted on two lucite disks in a copper disk mount in the manner illustrated in figures 1 and 2 .

An intermediate type of radio-balance, illustrated in figure 1, was also constructed, in which four Peltier junctions were bound with nylon thread to the cup, 2 above and 2 below the thermopile, to investigate the effect of distributing the cooling effect. However, apparently due to the fact that no part of the cup is ever very different in temperature from the surroundings at balance, this type had no advantages over that of simple construction and was, in fact, less satisfactory in use.

The Peltier current was derived from a $6-\mathrm{v}$ battery in series with a $1,000-0 h m$ variable resistance and a standard 1-ohm and standard 10-ohm coil. The value of the current flowing through the Peltier junctions was then determined by measuring the potential drop across either of the standard resistances by means of a potentiometer. The current from the thermopiles was measured by means of a high-sensitivity galvanometer of nominal sensitivity equal to $0.000029 \mu \mathrm{a} / \mathrm{mm}$. The thermopiles were connected either individually to the galvanometer or in opposition to each other through the galvanometer by means of mercury switches. A reversing switch made from three-contact mercury switches enabled the current through the galvanometer to be reversed. To eliminate extraneous thermal effects copper wire was used throughout, and the connections to the mercury switches and the switches themselves were immersed in an oil bath. An $18^{\circ}$ to $28^{\circ}$ $\mathrm{C}$ thermometer was used to measure the temperature of the copper block containing the radio-balance. This enables the variation in $P$ with temperature to be calculated, using the thermodynamical relation that

$$
P=T d E / d T,
$$

where $T$ is the absolute temperature, and $E$ is the thermoelectromotive force.

In the present series of experiments the performance of the radio-balance has been very extensively investigated by using ordinary commercial radium preparations contained in platinum-iridium needles having a wall thickness of $0.5 \mathrm{~mm}$.

The value of $P$ may be determined in a subsidiary experiment by measuring the variation of thermoelectromotive force with temperature of a thermocouple made from the same wire as that used to construct the Peltier junctions. This in fact was done, the thermoelectromotive force being measured at $25^{\circ}$ and $50^{\circ} \mathrm{C}$. In practice, however, a slight temperature gradient of a few hundredths of a degree will exist along the cup between its base, to which the Peltier junction is attached, and the equatorial ring of the thermocouple junctions. This means that the cooled cup will gain a small quantity of heat from the surroundings, and the heated cup will lose a corresponding amount. The net effect will be to decrease slightly the effective Peltier coefficient. It is better therefore to measure the Peltier coefficient under the conditions of the experiment in the radiobalance itself.

For the purpose of determining the Peltier coefficient in this way, two pairs of small resistance coils were wound on platinum wire to simulate the thermal conductivity of the platinum-iridium needles. Each pair of coils consisted of a main resistance $(R)$ with a compensating resistance $(r)$, consisting of only a few turns of wire, in series. One pair of coils was wound from 33 gage manganin and the other from 38 gage constantan wire. They were then impregnated with glyptal cement and baked. To determine the Peltier coefficient, a pair of coils was connected in series with the Peltier junctions, so that the same current flowed through the coils and the junctions. The coils were then inserted into the radio-balance, one into each cup. The current was then adjusted in magnitude and direction to give approximate balance of the thermopile galvanometer, and the value of the current and residual galvanometer deflection was determined. The coils were then interchanged between the two cups, the current reversed, and the new residual deflection measured. Knowing the value of the resistance of each coil, $W^{\prime}$ and $W^{\prime \prime}$ in eq (4) may be calculated, and $d_{1}, d_{2}$, and $C$ have been measured directly. The value of $s$ need only be known approximately as $d_{1}-d_{2}$ is, in general, only a small correcting term. The value of $P$ can thus be obtained directly with the help of eq (4). It should be noted that the energy dissipation of the coils appears in eq (4) as the difference between two wattages. The losses along the leads to the coils are, therefore, exactly compensated.

The approximate value of $s$ is determined by reversing a suitably small current through the Peltier junctions connected in opposition, with no source or coil in either cup, and noting the change in galvanometer deflection. Ideally, dummy radium needles should be placed in the two cups. As $W^{\prime}$ and $W^{\prime \prime}$ are now zero, $s$ can be determined directly from eq (4), using the thermoelectric value of $\dot{P}$ determined from eq (5).

The values of $R$ and $r$ were determined in terms of the standard resistances, using the potentiometer. For this purpose, the lead wires were bared, and potential leads were attached at equal distances from the point of the coil, which had previously rested on the base of the radio-balance cup. As already pointed out, only $W^{\prime}-W^{\prime \prime}$, and therefore $R-r$, is needed with accuracy. To obtain this, each coil was mounted on millimeter graph paper, and the distance from the 
point of the coil to the point where the potential leads were soldered was determined to less than onetenth of a millimeter. To enable this location to be made with accuracy and also to simulate the heat transfer of a radium needle, the platinum cores on which the two pairs of coils were wound, were turned to conical points, which protruded about a millimeter beyond the first turn of each coil at the end remote from the two current leads.

\section{Results}

TABLE 1. Resistances of calibrating coils

\begin{tabular}{|c|c|c|c|c|}
\hline Coils & $\begin{array}{l}\text { Distance from } \\
\text { pointed end of } \\
\text { coil to poten- } \\
\text { tial leads }\end{array}$ & $R$ & $r$ & $R-r$ \\
\hline $\begin{array}{l}\text { Manganin } \\
\text { Constantan } \\
\text { Do }\end{array}$ & $\begin{array}{l}c m \\
2.40 \\
2.30 \\
1.50\end{array}$ & $\begin{array}{r}\text { Ohms } \\
2.260 \\
10.047 \\
9.103\end{array}$ & $\begin{array}{l}\text { Ohms } \\
0.839 \\
3.225 \\
2.264\end{array}$ & $\begin{array}{l}\text { Ohms } \\
1.421 \\
6.822 \\
6.839\end{array}$ \\
\hline
\end{tabular}

The results obtained for $R-r$ for both the pair of manganin and the pair of constantan coils are shown in table 1 .

The results for the thermoelectric power $(d E / d T)$ from which the Peltier coefficient $(T d E / d T)$ may be determined are shown in table 2. These can be compared with the value of $61.2 \mu \mathrm{V} / \mathrm{deg}$ obtained at $25^{\circ} \mathrm{C}$ by direct measurement of the thermoelectric power.

TABLe 2. Mean thermoelectric power of Peltier junctions

\begin{tabular}{|c|c|c|c|}
\hline$R-r$ & Current & $\begin{array}{c}\text { Residual } \\
\text { deflection, } \\
d_{1}-d_{2}\end{array}$ & $\begin{array}{l}\text { Thermoelectric } \\
\text { power, } d E / d T\end{array}$ \\
\hline $\begin{array}{l}\text { Ohms } \\
\text { 1. } 421 \\
\text { 1. } 421 \\
\text { 1. } 421 \\
\text { 1. } 421 \\
6.831 \\
6.831\end{array}$ & $\begin{array}{c}m a \\
25.357 \\
25.629 \\
26.425 \\
28.060 \\
4.4735 \\
5.226\end{array}$ & $\begin{array}{c}m m \\
5.5_{5} \\
11.2 \\
19.6_{5} \\
43.65 \\
-7.0 \\
0.95\end{array}$ & $\begin{array}{l}\mu v / \mathrm{deg} \\
59.26 \times 10^{-6} \\
58.84 \\
59.17 \\
59.15 \\
59.09 \\
59.12\end{array}$ \\
\hline
\end{tabular}

The average of the first four values, for the manganin coils, is $59.12 \times 10^{-6} \mu \mathrm{v} / \mathrm{deg}$ at $25.4^{\circ} \mathrm{C}$; and the average of the last two values, for the constantan coils, is $59.10_{5} \times 10^{-6} \mu \mathrm{v} / \mathrm{deg}$ at $24.3^{\circ} \mathrm{C}$. An average value of $59.11 \times 10^{-6} \mu \mathrm{v} / \mathrm{deg}$ in the region of $25^{\circ} \mathrm{C}$ has therefore been assumed in calculating the results that follow.

Results for the scale sensitivity, $s$, for different currents and for different cup fillings are given in table 3.

After these preliminary calibrations, little remained to be done but to use the radio-balance, and it transpired that it was not necessary to limit its use to only the conventional method of balancing the energy dissipation of a radioactive source against the Peltier cooling. Experiments have been carried out chiefly with four radium preparations in platinumiridium needles. These preparations have been compared with the National Primary Radium Standard
TaBle 3. Galvanometer-scale sensitivity

\begin{tabular}{|c|c|c|c|c|}
\hline Cup fillings & Current & $2 P C$ & $\begin{array}{l}\text { Galva- } \\
\text { nometer } \\
\text { deflection }\end{array}$ & $\begin{array}{l}\text { Seale sensi- } \\
\text { tivity a }\end{array}$ \\
\hline $\begin{array}{l}\text { Silicone vacuum oil } \\
\text { only. }\end{array}$ & $\begin{array}{l}m a \\
3.097 \\
4.743 \\
6.081 \\
8.768\end{array}$ & $\begin{array}{l}\mu w \\
109.4 \\
167.5 \\
214.7 \\
309.6\end{array}$ & $\begin{array}{c}\mathrm{mm} \\
36.1_{5} \\
55.2_{5} \\
71.2_{5} \\
102.8_{5}\end{array}$ & $\begin{array}{c}m m / \mu w \\
0.330_{6} \\
.329_{9} \\
.331_{8} \\
.332_{2}\end{array}$ \\
\hline $\begin{array}{l}\text { 1-mg dummy needles } \\
\text { with silicone vacu- } \\
\text { um oil. }\end{array}$ & $\begin{array}{r}6.088 \\
11.903\end{array}$ & $\begin{array}{l}215.4 \\
421.2\end{array}$ & $\begin{array}{l}71.25 \\
139.5\end{array}$ & $\begin{array}{l}.330_{8} \\
.331_{2}\end{array}$ \\
\hline $\begin{array}{l}\text { 5-mg dummy needles } \\
\text { with silicone vacuum } \\
\text { oil. }\end{array}$ & $\begin{array}{r}2.996 \\
9.003 \\
15.008\end{array}$ & $\begin{array}{l}106.0 \\
318.6 \\
531.0\end{array}$ & $\begin{array}{c}35.0 \\
106.6 \\
176.45\end{array}$ & $\begin{array}{l}.330_{2} \\
.334_{6} \\
.332_{3}\end{array}$ \\
\hline
\end{tabular}

a A verage value of $s=0.331_{5} \mathrm{~mm} / \mu \mathrm{w}$.

and found, after correction for gamma-ray absorption in the platinum-iridium walls, to have the following values:

$\begin{array}{lr}\text { No. } 35915 \ldots & 10.19 \mathrm{mg} \text {, } \\ \text { No. } 35917 \ldots & 4.96 \mathrm{mg} \text {, } \\ \text { No. } 35919 \ldots & 1.049 \mathrm{mg} \text {, } \\ \text { No. } 35920 \ldots \ldots & 0.988 \mathrm{mg} \text {. }\end{array}$

If one of these sources be placed in cup $A$ and a dummy needle in cup $\mathrm{B}$, there will be an increase in the temperature of cup $\mathrm{A}$ and a corresponding deflection of the thermopile galvanometer. However, the largest of these sources, preparation 35915, causes a rise in temperature of the cup above its surroundings of only approximately $0.25 \mathrm{deg}$. C. The loss of heat by radiation and gaseous conduction through the surrounding air will therefore be quite negligible, and the heat will be carried away mainly by conduction through the Peltier and thermopile leads. This quantity of heat will therefore be proportional to the temperature difference, or, conversely, the rise in temperature of the cup will be directly proportional to the quantity of energy dissipated within it. In other words, the galvanometer deflection should be directly proportional to the quantity of energy dissipated within it, and is therefore, in turn, directly proportional, in the case of radium, to the quantity of radium in the needle. It is necessary to qualify this statement in the case of preparations of radium that have been sealed at widely different dates and to take into account the small differences in energy dissipation caused by the growth of $\mathrm{Po}^{210}$. With this qualification, however, the radio-balance has been found to provide an excellent method for quickly and accurately comparing the ratios of quantities of radium, simply by observing the ratios of the galvanometer deflections.

As an example of this method, the change in the galvanometer deflections on interchanging a radium source with a dummy between $\operatorname{cup} A$ and $\operatorname{cup} B$ is shown (fig. 5) plotted against milligrams of radium, for 3 of the 4 radium preparations used. Up to $5 \mathrm{mg}$ of radium the scale deflection is a linear function of the mass of radium, but in order to preserve linearity up to $10 \mathrm{mg}$, it was necessary to convert scale deflections to angular deflections. 


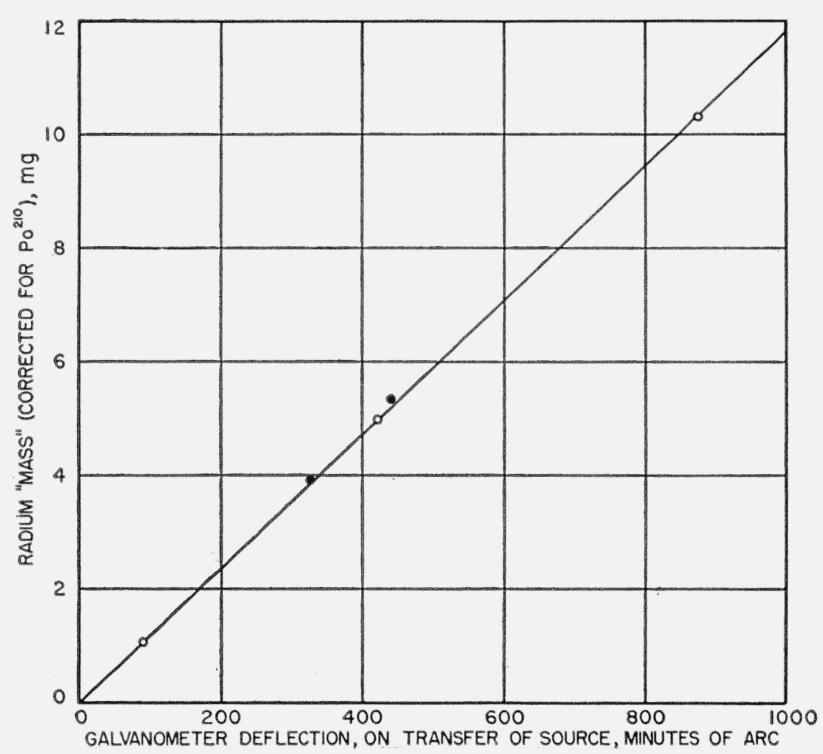

Figure 5. Galvanometer deflection in minutes of arc as a function of milligrams of radium transferred from cup $A$ to cup $B$.

Open circles are for sources 35919,35917 , and 35915. Solid circles are difference readings for source 35919 and source $35917(=3.91 \mathrm{mg}$ of $\mathrm{Ra}$ ) and for source 35917 and source $35915(=5.23 \mathrm{mg}$ of $\mathrm{Ra}$ ). In order to reduce all readings to a comparable norm the milligram content has been increased by the ratio of column 4 to column 5 in table 5 to allow for the fact that the radium content, as determined by gamma-ray measurements, does not take into account the growth of polonium. The stated accuracy of the certification of the Radium Testing Laboratory is The stated accuracy of the certification of the Radium Testing Laboratory is
\pm 0.7 percent. This uncertainty in mass is approximately represented by the \pm 0.7 percent. This uncertainty in mass is approximately represented by the
diameter of the open circles for the $10.19-\mathrm{mg}$ source $(=10.32 \pm 0.07 \mathrm{mg}$, corrected for polonium).

It should perhaps be emphasized at this juncture that the energy emitted in the form of gamma radiation is largely lost from the radio-balance. With radium in equilibrium with its short-lived daughters, alpha radiation accounts for about 87 percent of the energy emission, recoil nuclei for about 2 percent, primary beta radiation for about 4 percent, and gamma radiation and secondary beta radiation for about 7 percent. Polonium in equilibrium would contribute a further 20 percent.

The energies dissipated by sources 35915,35917 , 35919 , and 35920 were now measured by the transfer method between cups $\mathrm{A}$ and $\mathrm{B}$, using the Peltier cooling and heating to equalize source and dummy, respectively. It later transpired that these sources, although purchased at the same time, had been sealed at different dates and it therefore became necessary to correct for the growth of the $5.3-\mathrm{Mev}$ alpha particle due to $\mathrm{Po}^{210}$. This was done by using a relation derived by Curie and Yovanovitch [4], who neglected the effect of the short-lived intermediaries between radium and radium $\mathrm{D}$ and between radium $\mathrm{D}$ and polonium. This relation, the numerical constants of which were later revised by Sanielevici [5], Zlotowski [6], and then by Jordan [7], using more accurate half-life data, gives $Q_{\alpha_{\mathrm{P} 0}}$, the heat generated by the $\mathrm{Po}^{210}$ alpha particles, as a function of the time $t$ in years as follows:

$$
\begin{gathered}
Q_{\alpha_{0}}=27.26\left(1-1.0175 e^{-0.03108 t}+0.0173 e^{-1.829 t}\right) \mathrm{cal} \mathrm{g}^{-1} \\
\mathrm{hr}^{-1}(6)
\end{gathered}
$$

The results obtained are summarized in table 4 . All sources are corrected for polonium growth to October 1953.

The ratios of these sources obtained by gamma-ray comparisons in the Bureau's Radium Testing Laboratory and by the radio-balance are summarized in table 5. The stated accuracy of the Radium Testing Laboratory results is \pm 0.7 percent.

Values obtained at other times for the energy emission of sources 35917 and 35919 are given in table 6 .

Values for source 35917 were also determined by using cup A and cup B individually. For this purpose, it is necessary to determine the resistance $R_{\mathrm{A}}$ and $R_{\mathrm{B}}$ of the Peltier junctions to cups $\mathrm{A}$ and $\mathrm{B}$. Using eq (2), these were found to be $46.30 \times 10^{-3}$ and $46.07 \times 10^{-3} \mathrm{ohm}$, respectively. As has been mentioned previously, however, it is difficult to remove completely the residual thermopile zero deflections for each cup individually. In this determination therefore these zero deflections were determined initially, and the values for the source energy emission were reduced to these afterward by extrapolation. However, this method is tedious compared with the transfer method. The results obtained by using eq (1) are shown in table 7.

One final point of note is that the radio-balance can be used to compare two nearly equal sources by the transfer method without using any Peltier current at all. From figure 5 the scale sensitivity for transfer of a mass of radium from cup A to cup B is 0.0193 $\mathrm{mg} / \mathrm{mm}$. On placing source 35919 in cup A and source 35920 in cup B, an out-of-balance deflection of $+1.9 \mathrm{~mm}$ was observed. On interchanging the sources, an out-of-balance deflection of $-1.4 \mathrm{~mm}$ was observed, giving a total change on transfer of 3.3 $\mathrm{mm}$. In actual practice, twice this deflection is observed on reversing the current through the galvanometer, but for convenience in recognizing whether cup $\mathrm{A}$ is warmer or cooler than cup $\mathrm{B}$, these are reduced to half the deflection to the right $(+)$ or left (-) of zero.

A change of deflection on transfer corresponds therefore to a difference between sources 35919 and 35920 of $0.064 \mathrm{mg}$, with 35919 the greater (a positive deflection corresponds to cup $A$, being at a higher temperature than cup B).

Thus if we assume that source 35919 consists of $1.049 \mathrm{mg}$ of radium, as certified by the Radium Testing Laboratory, then source 35920 comprises 0.985 $\mathrm{mg}$ (compared with $0.988 \mathrm{mg}$ as certified by the Radium Testing Laboratory).

This application is also illustrated for widely differing sources in figure 5 , where points derived by taking differences between sources 35915,35917 , and 35919 have been plotted.

A series of experiments was also carried out with the radio-balance, using individual cups in an evacuated bell jar at approximately $5 \times 10^{-5} \mathrm{~mm} \mathrm{Hg}$ pressure, with a view to determining whether the loss of heat from the cups by radiation and gaseous conduction was of significance. In general, it was found 
TABLE 4. Energy dissipation per milligram of radium

\begin{tabular}{|c|c|c|c|c|c|c|c|}
\hline Source & Date sealed & Value & $\begin{array}{c}\text { Balancing } \\
\text { current }\end{array}$ & $\begin{array}{c}\text { Change of re- } \\
\text { sidual galva- } \\
\text { nometer deflec- } \\
\text { tion on transfer, } \\
\left(d_{1}-d_{2}\right)\end{array}$ & $\begin{array}{l}\text { Energy dis- } \\
\text { sipation }\end{array}$ & $\begin{array}{l}\text { Energy dis- } \\
\text { sipation per } \\
\text { milligram of } \\
\text { radium }\end{array}$ & $\begin{array}{l}\text { Energy dissipa- } \\
\text { tion of radium } \\
\text { less the polo- } \\
\text { nium contri- } \\
\text { bution a }\end{array}$ \\
\hline $\begin{array}{l}35915 \\
35917 \\
35919 \\
35920\end{array}$ & $\begin{array}{l}\text { April } 6,1951 \\
\text { November 6, } 1952 \\
\text { December 22, } 1949 \\
\text { December } 22,1949\end{array}$ & $\begin{array}{c}m g \mathrm{Ra} \\
10.19 \\
4.96 \\
1.049 \\
0.988\end{array}$ & $\begin{array}{c}m a \\
42.674 \\
21.587 \\
3.850 \\
3.855\end{array}$ & $\begin{array}{c}m m \\
11.8 \\
-4.15 \\
8.0 \\
5.2\end{array}$ & \begin{tabular}{r}
\multicolumn{1}{c}{$\mu w$} \\
1541.1 \\
749.0 \\
159.9 \\
151.7
\end{tabular} & $\begin{array}{c}\mu w / m g \mathrm{Ra} \\
151.2 \\
151.0 \\
152.4 \\
153.5\end{array}$ & $\begin{array}{c}\mu w / m g \mathrm{Ra} \\
149.3 \\
150.5 \\
149.4 \\
150.5\end{array}$ \\
\hline
\end{tabular}

s A verage energy dissipation per milligram of radium (less $\mathrm{P}_{\mathrm{o}}{ }^{210}$ contribution) equals $149.9 \mu \mathrm{w} / \mathrm{mg} \pm 0.4$ percent, which is equal to 128.9 cal g-1 $\mathrm{hr}^{-1} \pm 0.4$ percent. ( \pm 0.4 percent represents a 95-perent confidence limit.)

TABLE 5. Measured relative values of radium sources

\begin{tabular}{|c|c|c|c|c|c|}
\hline \multirow[b]{2}{*}{ Source } & \multicolumn{2}{|c|}{$\begin{array}{l}\text { NBS Radium Testing } \\
\text { Laboratory }\end{array}$} & \multicolumn{3}{|c|}{ Radio-balance } \\
\hline & Value & Ratios & $\begin{array}{c}\text { Energy } \\
\text { dissipation }\end{array}$ & $\begin{array}{l}\text { Energy dissi- } \\
\text { pation less } \\
\text { polonium } \\
\text { contribution }\end{array}$ & Ratios \\
\hline $\begin{array}{l}35915 \\
35917 \\
35919 \\
35920\end{array}$ & $\begin{array}{c}m g \\
10.19 \\
4.96 \\
1.049 \\
0.988\end{array}$ & $\begin{array}{l}1 \\
0.487 \\
.1029 \\
.0970\end{array}$ & $\begin{array}{r}\mu w \\
1541.1 \\
749.0 \\
159.9 \\
151.7\end{array}$ & $\begin{array}{r}\mu w \\
1521.8 \\
746.0 \\
156.8 \\
148.6\end{array}$ & $\begin{array}{l}1 \\
0.490 \\
.1030 \\
.0976\end{array}$ \\
\hline
\end{tabular}

TABLE 6. Energy dissipation of two radium sources

\begin{tabular}{|c|c|l|}
\hline Source & $\begin{array}{c}\text { Energy dissi } \\
\text { pation less } \\
\text { polonium } \\
\text { contributions }\end{array}$ & $\begin{array}{c}\text { Date of } \\
\text { measurement }\end{array}$ \\
\hline & & \\
\hline 35917 & 743.3 & September 1, 1953. \\
35917 & 744.3 & $\begin{array}{c}\text { Do. } \\
35917\end{array}$ \\
3517 & 748.7 & September 24, 1953. \\
35917 & 748.7 & September 22, 1953. \\
35919 & 159.0 & October 22, 1953. \\
35919 & 158.8 & September 1, 1953. \\
35919 & Do. \\
35919 & 156.6 & Do. \\
\hline & 156.8 & October 22, 1953. \\
\hline
\end{tabular}

a The mean value for source 35917 is $746.3 \mu \mathrm{w}$, with a standard deviation of 0.3 percent. The mean value for source 35919 is $157.8 \mu \mathrm{w}$, with a standard deviation of 0.8 percent

No dummy used in other cup.

TABLE 7. Determination of the energy emission from a radium source, using the radio-balance cups individually

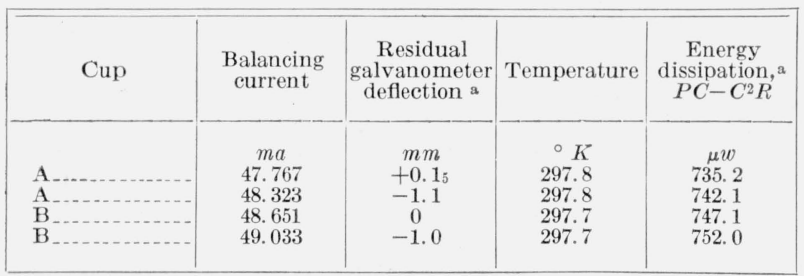

a The initial "zero" deflections for cups A and B, with a dummy 5-mg needle that had been left to come into thermal equilibrium in each, were -1.3 and $-1.0 \mathrm{~mm}$, respectively. Thus the value of source 35917 as determined in cup A is, by extrapolation, $743.2 \mu \mathrm{w}$. The value for cup B is 752.0 $\mu \mathrm{W}$. The average value for cups $\mathrm{A}$ and $\mathrm{B}$ is $747.6 \mu \mathrm{W}$ (or $745.3 \mu \mathrm{W}$ after correct$\mu \mathrm{W}$. The average value for cups A and B is $747.6 \mu \mathrm{W}$ (or $745.3 \mu \mathrm{W}$ after correct-
ing for the growth of polonium) compared with $746.5 \mu \mathrm{W}$ obtained by the transfer method (also corrected for polonium growth).!

that the radio-balance was much more unruly, the extraneous thermal effects being more difficult to track down and eliminate. This method of using the radio-balance was therefore abandoned in favor of the methods described. The use of silicone vacuum- pump oil originated, however, from the experiments with the apparatus in a vacuum, but its use was continued because of the obvious advantage of a lowvapor-pressure liquid from the point of view of avoiding decreases in temperature due to evaporation.

\section{Comparison With the Mound Laboratory Calorimeters}

As the total energy emission of two radium needles, the milligram content of which had been measured in terms of the National Primary Radium Standard, had recently been measured in the calorimeters of the Mound Laboratory, it has been possible to compare their results with those obtained with the radiobalance.

The total radium content of these two radium sources as measured by the Radium Testing Laboratory was $10.20 \mathrm{mg}$.

The Mound Laboratory obtained results both with their microcalorimeter and their macrocalorimeter. With the former they found the total energy output of the two needles to be $1.634 \mu \mathrm{w}$, with $0.1 \mathrm{~cm}$ equivalent lead absorption; with the latter, they found it to be $1.65 \mu \mathrm{w}$, with $1.1 \mathrm{~cm}$ equivalent of lead absorption.

Initially, it was assumed by the Mound Laboratory that these needles had been sealed recently. However, it has transpired that they had been first tested by the National Bureau of Standards in June 1939, and that considerable correction had to be made for the growth of $\mathrm{Po}^{210}$.

By using a value of $4.185 \mathrm{j} / \mathrm{cal}$ and the value of $10.20 \mathrm{mg}$ of radium, the Mound Laboratory results reduce to $137.8 \mathrm{cal} \mathrm{g}^{-1} \mathrm{hr}^{-1}$ (microcalorimeter, 0.1 $\mathrm{cm} \mathrm{Pb}$ equivalent) and $139.2 \mathrm{cal} \mathrm{g}^{-1} \mathrm{hr}^{-1}$ (macrocalorimeter, $1.1 \mathrm{~cm} \mathrm{~Pb}$ equivalent), both uncorrected for $\mathrm{Po}^{210}$ growth and therefore including all energy contributions down to that due to the $\mathrm{Po}^{210}$ alpha particles.

The cups of the radio-balance are $0.04 \mathrm{~cm}$ thick; in each case the wall thickness of the platinumiridium needle was $0.05 \mathrm{~cm}$. As the mass-absorption coefficients of copper, platinum, and lead are, for the purpose of making a gamma-ray absorption correction in this energy range, sufficiently near to equality, and as the needles consist of 90 percent of platinum, it will be sufficiently accurate to reduce the absorption of the platinum-iridium needles and the copper cups for gamma radiation to their equiva- 
lent total absorption in lead using the densities of copper, platinum, and lead. This gives a gammaray absorption of the needles and cups equivalent to that of $0.126 \mathrm{~cm}$ of lead.

Assuming that the radium needles had been sealed for 14 years prior to their measurement by the Mound Laboratory between December 1952 and February 1953, the contripution due to $\mathrm{Po}^{210}$ would have been $9.5 \mathrm{cal} \mathrm{g}^{-1} \mathrm{hr}^{-1}$, as calculated from eq (6). We have, therefore, the following results for the energy output of $1 \mathrm{~g}$ of radium and its products down to radium $\mathrm{D}$ :

$128.3 \mathrm{cal} \mathrm{g}^{-1} \mathrm{hr}^{-1}$

129.7 cal g $^{-1} \mathrm{hr}^{-1}$

Mound microcalorimeter with 0.1 $\mathrm{cm} \mathrm{Pb}$ equivalent.

Mound macrocalorimeter with 1.1 $\mathrm{cm} \mathrm{Pb}$ equivalent. $\begin{aligned} 128.9 \mathrm{cal} \mathrm{g}^{-1} \mathrm{hr}^{-1} \ldots & \text { NBS radio-balance with } 0.126 \mathrm{~cm} \\ & \text { Pb equivalent. }\end{aligned}$

These results have been reduced, for the purpose of comparison, to the same value of equivalent absorption, using the measurements of Zlotowski [6], who determined the energy emission of four radium sources calorimetrically by using different thicknesses of lead absorber around the sources. Zlotowski's results are shown in figure 6 , where the heat absorbed in the calorimeter is plotted as a function of thickness of lead absorber. By using this curve the Mound Laboratory results may be reduced to an equivalent thickness of lead equal to $0.126 \mathrm{~cm}$ and compared directly with the NBS value. The results then obtained are

Mound microcalorimeter

Mound macrocalorimeter

$128.5 \mathrm{eal} \mathrm{g}^{-1} \mathrm{hr}-1$.

$125.4 \mathrm{cal} \mathrm{g}^{-1} \mathrm{hr}-1$.

NBS radio-balance.

128.9 eal g $^{-1} \mathrm{hr}^{-1}$.

The probable error of the mean value obtained from 10 readings with each of the Mound calorimeters is \pm 0.5 percent. The probable error of the mean value obtained from 4 readings of the NBS radio-balance is \pm 0.2 percent.



FIgURE 6. Heat absorbed from $1 \mathrm{mg}$ of radium per hour as a function of equivalent absorption in lead, after Zlotowski [6].

The point at $7 \mathrm{~cm}$ of $139.6 \mathrm{cal} \mathrm{g}^{-1} \mathrm{hr}^{-1}$ is the extrapolated value for the total heat emission of radium-226 and its daughters down to $\mathrm{Ra} \mathrm{C}^{\prime}$.

\section{Conclusion}

It is proposed to apply the radio-balance described in this paper to the measurement of the average energy of beta emitters and also to a number of other appropriate problems. A new radio-balance is being constructed with a view to comparing the U. S. and Canadian National radium standards. Two such standards were compared with quite promising results in the radio-balance here described, but the cups of this radio-balance are somewhat too small for these sources. It is interesting to note, however, that the radio-balance is so responsive that a comparison agreeing well with the known data was carried out between the U. S. and Canadian National radium standards in as short a time as $1 \mathrm{hr}$.

From table 3 the average value of the scale sensitivity for transfer is $0.332 \mathrm{~mm} / \mu \mathrm{w}$. As deflections may be read to about $0.1 \mathrm{~mm}$ (i. e., $0.2 \mathrm{~mm}$ on reversal of the current through the galvanometer), it should be possible to determine an energy emission to about a third of a microwatt. Thus a $30-\mu \mathrm{w}$ source should be susceptible of measurement with an accuracy of about 1 or 2 percent. Such a value, corresponding to about $0.2 \mathrm{mg}$ of radium, probably represents the lower limit of usefulness of the radiobalance.

Grateful acknowledgment is made to D. L. Timma and to K. C. Jordan of the Mound Laboratory of the Monsanto Chemical Co., for their courtesy in carrying out the calorimetric measurements on the two radium needles that had been calibrated by the NBS Radium Testing Laboratory in terms of the National Primary Radium Standard. Thanks are also expressed to T. I. Davenport of the Radium Testing Laboratory for suggesting and arranging that these radium needles should be measured by the Mound Laboratory, and to him and his colleagues, C. C. McCraven and L. F. Paolella, for supplying a number of calibrated radium needles for frequent rechecks of their values, and also for valuable assistance in the construction of the radio-balance container. Also gratefully acknowledged is the kind assistance of Chester Peterson, of the NBS Resistance and Reactance Section, for his calibration of the standard resistances used and for the loan of a standard cell; Joseph A. Kelly, Jr., vice president of the Radium Chemical Co., for the loan of two 1-mg and two 5-mg empty platinum-iridium needles for use as dummy sources; and of S. Eugenia Thomas, of the Temperature Measurements Section, for measuring the thermoelectric power of a number of thermocouples constructed from the chromel and constantan wires used to make the Peltier junctions.

\section{References}

[1] H. L. Callendar, Proc. Phys. Soc. (London) 23, 1 (1911).

[2] F. E. Hoare, Phil. Mag. 6, 828 (1928).

[3] F. E. Hoare, Phil. Mag. 13, 386 (1932).

[4] M. Curie and D.-K. Yovanovitch, J. phys. radium 6, 33 (1925)

[5] A. Sanielevici, J. chim. phys. 30, 513 (1933)

[6] I. Zlotowski, J. phys. radium 6, 242 (1935).

[7] K. C. Jordan, private communication.

Washington, November 17, 1953. 